\title{
Ballistic-damage-induced size changes in equilibrium and under- pressurized Xe precipitates in amorphous silica
}

Anamul H. Mir ${ }^{*}$, Jonathan A. Hinks ${ }^{1}$, Stephen E. Donnelly ${ }^{1}$

${ }^{1}$ School of computing and engineering, University of Huddersfield, Queensgate Huddersfield, HD1 3DH United

Kingdom

"Corresponding author: A.H. Mir (a.h.mir@hud.ac.uk ; mirinamulhaq@gmail.com)

Citation: J. Nucl. Mater. 519, 229-238 (2019).

\begin{abstract}
This work explores the behaviour of xenon precipitates in amorphous silica using a transmission electron microscope with in-situ ion implantation. The specimens were first implanted at high-temperature to form equilibrium Xe precipitates which were then cooled to room temperature to form under-pressurized precipitates. Insitu implantation and real-time monitoring at high and room temperature were used to study the behaviour of the equilibrium and under-pressurized precipitates, respectively. The study at high-temperature revealed that the precipitates grow under equilibrium conditions until saturation is reached. Subsequent to precipitate growth under equilibrium conditions, the specimens contain a mixture of equilibrium, under-pressurized and possibly overpressurized precipitates in addition to voids. Unlike precipitates growth at high-temperature $(873 \mathrm{~K})$, underpressurized precipitates; formed after cooling the specimen implanted at $873 \mathrm{~K}$ to room temperature, considerably shrank in size when subjected to further ion implantation. The shrinkage continued until a new equilibrium state defined by the room temperature density of the Xe precipitates was achieved. We discuss the growth and shrinkage of the precipitates in terms of the ballistic thermal spike which initiates Xe diffusion from the matrix into the precipitates at high-temperature and convective flow of the glass towards the under-pressurized precipitates and voids causing their shrinkage at room temperature.
\end{abstract}

Keywords: TEM, Irradiation, xenon, precipitates, bubbles, silica

\section{Introduction}

A number of studies have been performed on noble gas precipitates in a wide variety of materials, such as; metals [1-11], semiconductors [12-14], alloys [15-17], glasses [18-20] and ceramics [21][22]. Most of these studies were aimed at exploring the conditions under which noble gas precipitates form and evolve and address any detrimental effects that this may lead to in structural nuclear reactor materials (e.g. fuel, cladding and first-wall materials) and nuclear waste matrices (e.g. glasses, ceramics and composite materials). Besides the nuclear industry, the studies on noble gas precipitation in dielectrics (e.g. glasses) has also drawn the attention of the electronics industry as a means of tailoring the dielectric properties of these materials [23][24]. Understanding the fundamental behaviour of noble gas precipitates (such as their growth, coalescence and re-solution; precipitate to void transformation; and the degree of internal pressure) requires detailed studies, especially, in-situ monitoring of their dynamics. The estimate of internal pressure is an important parameter for predicting precipitate growth, coalescence, inter-bubble fracture and surface blistering as it is required in some of the predictive models dealing with these aspects [25][16].The majority of the studies in this domain have mainly focussed on crystalline materials (metals and ceramics) and there is generally a lack of studies on the subject of internal pressure and its effect on the dynamics of precipitates in amorphous materials and especially glasses. Based on the formation of $\mathrm{He}$ and Ar bubbles in amorphous alloys $\left(\mathrm{Fe}_{40} \mathrm{Ni}_{38} \mathrm{Mo}_{4} \mathrm{~B}_{18}\right)$ [16][17], two slightly different theoretical models with a few free parameters to fit the experimentally observed bubble growth have been proposed for bubble growth under implantation in amorphous materials. The basic model is the constant excess pressure model (CEP model) [16]. The second model (CEPcascade model) - which itself is based on the CEP model - emphasises the contribution of ballistic collision cascades in bubble growth. The CEP model assumes that the bubbles have a constant excess pressure throughout their growth process and that this excess pressure, on reaching a certain critical limit, is responsible for pushing the bubble boundary outwards. The excess pressure is a result of gas diffusion into the bubbles, bubble coalescence and also direct implantation of gas atoms into the bubbles. Besides gas diffusion, bubble coalescence plays an important role in this model and a coalescence dependent free parameter is usually varied to fit the experimental bubble growth data. The CEP-cascade model, in addition, assumes that the bubble boundary can be pushed outwards during the collision cascade itself due to the pre-existing excess pressure (therefore, reaching a critical pressure limit is not necessary for bubble growth) which drives the void-type defects towards the bubbles during a collision cascade leading to their growth. The existence of excess pressure is thus a necessary criterion and the fundamental basis of these models. The models predict an excess pressure requirement of about $50 \mathrm{GPa}$ (or between 20 to 100 
GPa for the CEP-Cascade model). The radii of the bubbles considered in these models range from about 1-13 nm and implies a pressure which is significantly higher than the equilibrium pressure of the bubbles; which is usually less than $5 \mathrm{GPa}$ in most of the cases. To date, no experimental evidence of the existence of such high excess pressures in amorphous materials has been reported. Our recent studies of noble gas precipitates in amorphous-SiO $\mathrm{S}_{2}$ $\left(\mathrm{a}-\mathrm{SiO}_{2}\right)$ supplemented by Monte-Carlo simulations (in addition to the current study) have shown that the precipitates exist as supercritical fluid inclusions and not as solid inclusions as would be expected at such high excess pressures [20]. Therefore, the requirement that bubbles are under constant excess pressure which can range up to $100 \mathrm{GPa}$ needs revisiting or at least needs discussing in terms of its feasibility for use in glasses. Whether the existence of constant excess pressure is a necessary criterion for bubble growth in glasses is thus worth exploring at both cryogenic and at high temperatures with some emphasis on the bubble size dependence of the excess pressure. Irrespective of the material type, there are currently no systematic experimental studies specifically looking at the effect of the degree of internal pressure on the dynamics such as growth, coalescence and re-solution of the precipitates. This is especially true for under-pressurized bubbles/precipitates which have received hardly any attention in the literature. Molecular dynamics simulations [26] and some experimental studies [13][14] on the behaviour of voids in silicon have shown that voids are unstable to ion irradiation. It has been proposed that the lack of internal pressure allows mass flow towards the voids during the ballistic phase leading to their closure. If one were to emphasize the role played by the internal pressure, under-pressurized precipitates would then be expected to behave partly like voids and show a limited degree of resistance to closure under ion irradiation. It is plausible to propose that in going from under-pressurized to over-pressurized precipitates/bubbles, the dynamics of precipitate growth will change from negative (shrinkage) to positive (growth).

The first aim of this article is to show that the existence of excess pressure as predicted by certain models is not a necessary criterion for bubble/precipitate growth in glasses. Secondly, we explore the impact of internal pressure on the dynamics of the precipitates and show that under-pressurized precipitates are partially stable to ion irradiation and show shrinkage as would be expected from the already known behaviour of voids. This work focuses on the formation of Xe precipitates in amorphous $\mathrm{SiO}_{2}\left(\mathrm{a}-\mathrm{SiO}_{2}\right)$ using a Transmission electron microscope (TEM) with in-situ ion implantation. In order to shed light on the physical processes that can explain the growth of the precipitates during implantation, thermal spike simulations have been performed to look at the extent to which the temperature spikes experienced during the ballistic phase of the collision cascades enable Xe diffusion.

\section{Experiments}

\subsection{Specimen preparation and ion implantation}

Thin TEM specimens of a-SiO $\mathrm{S}_{2}$ were obtained by focussed ion beam milling using $30 \mathrm{keV} \mathrm{Ga}$ ions. The specimens were then implanted at $873 \mathrm{~K}$ and $295 \mathrm{~K}$ with $45 \mathrm{keV}$ Xe ions inside a Hitachi-H-9500 TEM with in-situ ion implantation at the MIAMI-2 facility at the University of Huddersfield. Initially, the specimen was heated to $873 \mathrm{~K}$ using a heating rate of $100 \mathrm{~K}$ per minute. After holding for 15 minutes at this temperature, the specimen was implanted with Xe ions at a flux of $1.6 \times 10^{13}$ ions. $\mathrm{cm}^{-2} \cdot \mathrm{s}^{-1}$. The electron beam was switched off during ion implantation to minimise any electron-beam-induced effects. The observations of Xe precipitate formation were made with increments of $2 \times 10^{15} \mathrm{Xe} . \mathrm{cm}^{-2}$. An electron flux of $9 \times 10^{17}$ electrons.cm ${ }^{-2} . \mathrm{s}^{-1}$ was used to capture the bright-field TEM images (BF-TEM) with an objective aperture of $8.5 \mathrm{mrad}$ collection angle and a typical exposure time of $0.5 \mathrm{~s}$. After a Xe implantation fluence of $7.5 \times 10^{15}$ ions.cm ${ }^{-2}$, electron beam at a flux of $1.6 \times 10^{18}$ electrons. $\mathrm{cm}^{-2} . \mathrm{s}^{-1}$ was switched on to record in-situ videos of Xe ion-implantation induced changes in the Xe precipitates (studies showing electron beam exposure at such intensities for few minutes does not have a measurable effect were carried out prior to this). The specimen was irradiated up to a fluence of $1.24 \times 10^{16} \mathrm{Xe} . \mathrm{cm}^{-2}$ in this manner to record the real-time dynamics taking place. After this, the specimen was cooled to $295 \mathrm{~K}$ and after waiting for about 12 minutes at $295 \mathrm{~K}$, the specimen was again irradiated with Xe ions and in-situ videos were again captured.

\section{Results}

\subsection{Effect of Xe implantation at $873 \mathrm{~K}$}

Xe implantation at $873 \mathrm{~K}$ resulted in the formation of Xe precipitates. The first Xe precipitates were formed after implantation with $6 \times 10^{15} \mathrm{Xe} . \mathrm{cm}^{-2}$ ( 2 atomic $\%$ on average under the implantation profile; see Fig. S1 in the SI for implantation profile). BF-TEM images of the Xe precipitates after implantation with $7.5 \times 10^{15} \mathrm{Xe} . \mathrm{cm}^{-2}$ are shown in Fig.1 (a-c) in different focussing conditions. The single bright feature seen in the micrograph as indicated by the black arrow is a void (based on the work in [20]) and the rest of the circular features are Xe precipitates. All the precipitates are invisible in the at-focus images - which, based on our previous work [20] on this subject, indicates that these precipitates should have a Xe density in the range of 0.5 to $1.5 \mathrm{~g} . \mathrm{cm}^{-3}$. 

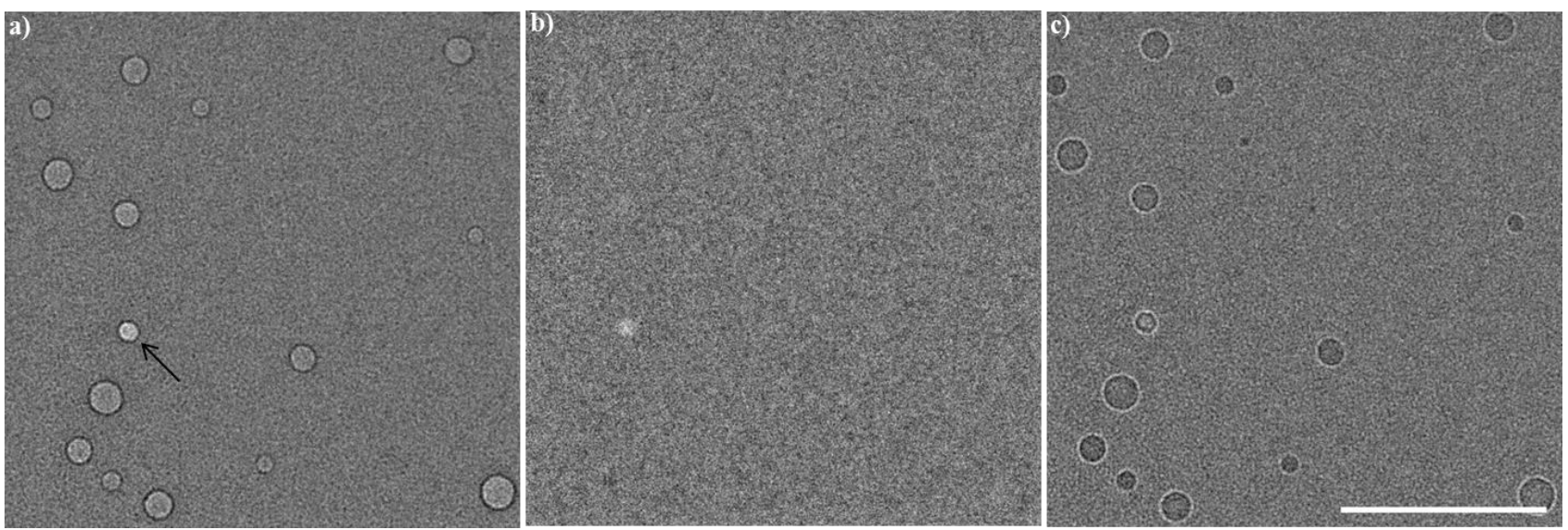

Figure-1: BF-TEM micrographs of a-SiO ${ }_{2}$ implanted with $45 \mathrm{keV} \mathrm{Xe} \mathrm{ions} \mathrm{to} 7.5 \times 10^{15} \mathrm{Xe.cm}{ }^{-2}$ at $873 \mathrm{~K}$. (a) Under-focus, (b) at-focus and (c) over-focus images. The arrow in (a) indicates a void. (defocus $=4 \mu \mathrm{m}$, scale marker $=200 \mathrm{~nm}$ for all the images).

Upon further implantation, the precipitates continuously grew in size and reached a steady state. They then transformed into voids which shrank in size and eventually closed due to continued ion implantation. This dynamic behaviour captured in-situ during ion implantation is shown in video SV01 in the SI. Video stills showing the dynamics of the precipitate growth, transformation into a void and shrinkage of the void are shown in Fig.2. The fluence at the first frame (A1) is $7.5 \times 10^{15} \mathrm{Xe} . \mathrm{cm}^{-2}$ and then in sequentially moving across the rows, there is an increment of $1.58 \times 10^{14}$ ions. $\mathrm{cm}^{-2}$ per frame. The fluence at the last frame (F5) is $1.2 \times 10^{16} \mathrm{Xe} . \mathrm{cm}^{-2}$. The A1 frame shows a single precipitate which grows until frame D3 and then transforms into a void - visible as a relatively brighter feature in the E3 frame. The void then shrinks upon further ion irradiation and is no longer visible in frame F5. A second precipitate can be seen to emerge in frames C1/D1 as indicated by the arrows in the first few frames of its evolution. It grows until frame B5 and then transforms into a void, which shrinks upon further ion implantation. This is the general trend followed by all the precipitates and voids as seen in the video SV01 in the SI. 


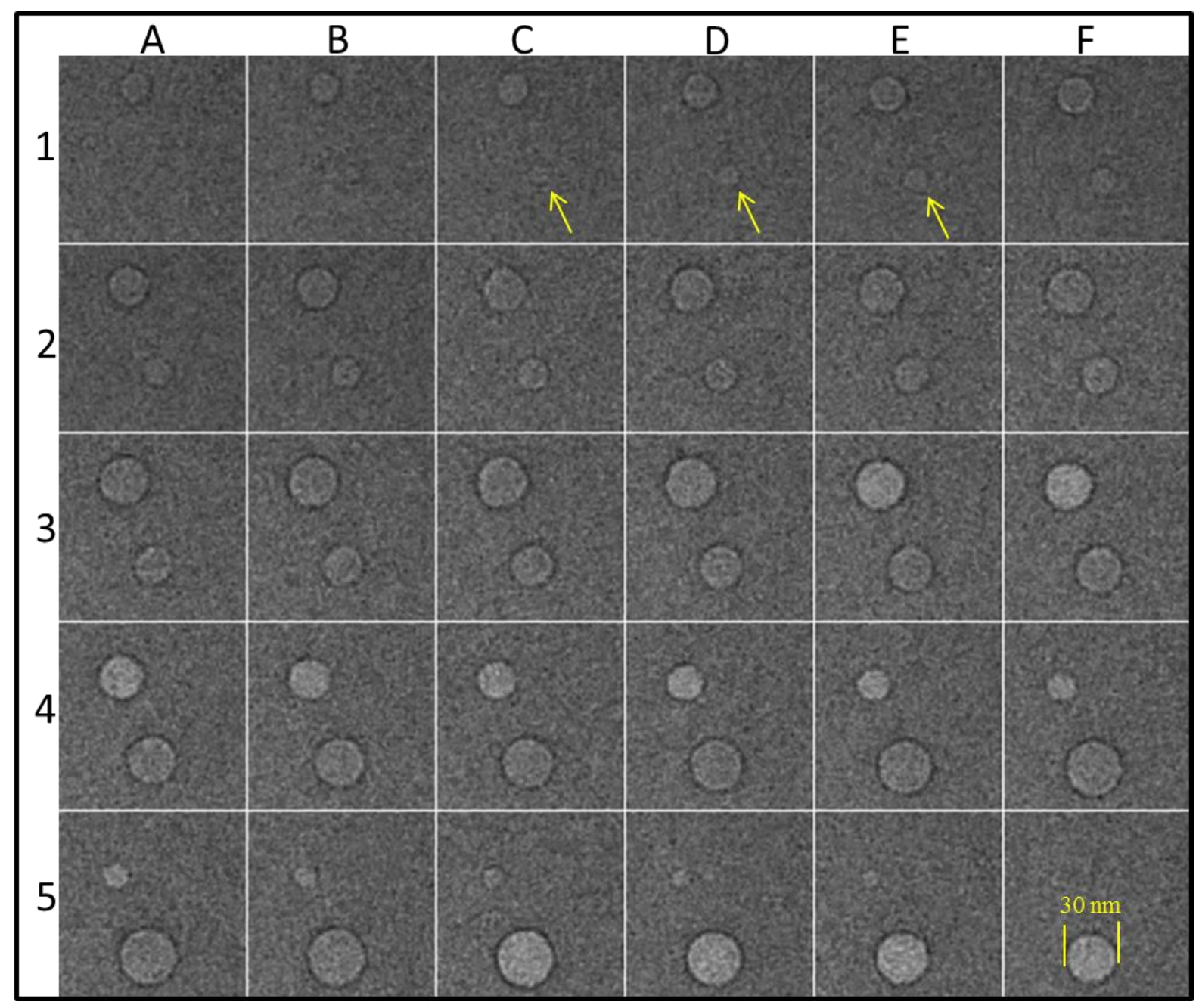

Figure-2: Video stills from the in-situ video shown in SV01 in the SI. The images show $45 \mathrm{keV}$ Xe implantation induced growth and shrinkage of the Xe-precipitates and voids at $873 \mathrm{~K}$, respectively. Fluence of the first frame $=7.5 \times 10^{15} \mathrm{Xe} . \mathrm{cm}^{-2}$, fluence increment per frame $=1.58 \times 10^{14} \mathrm{Xe} . \mathrm{cm}^{-2}$ and fluence of the last frame $=1.2 \times 10^{16} \mathrm{Xe} . \mathrm{cm}^{-2}$. The arrows indicate the emergence of a precipitate (Defocus $=4$ um under-focus).

The increase in the projected area of some of the precipitates as a function of the implantation fluence, their tendency to reach a steady state (plateau) and then shrink is shown in Fig.3 (different precipitates labelled 1 to 5). The projected area of the precipitates and voids was measured using Fiji software [27] by manually fitting circles around the features. The slopes of the linear regions of the curves; indicated by the rectangles for curve-1 in Fig. 3 , are $25 \pm 4 \mathrm{~nm}^{2}$ and $38 \pm 6 \mathrm{~nm}^{2}$ per unit fluence (ions. $\mathrm{nm}^{-2}$ ) in the growth and shrinkage regions, respectively. This shows that the voids shrink at a greater rate than the growth rate of the precipitates. This behaviour of the precipitates and voids has an effect on their size distributions as we briefly discuss later. 


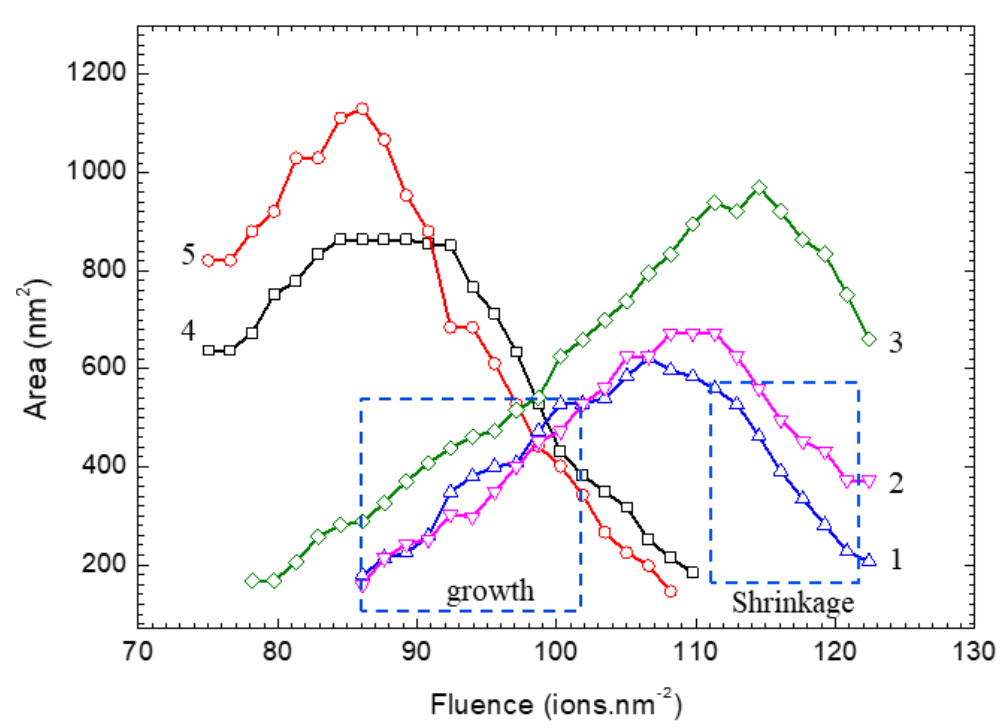

Figure-3: Xe ion implantation induced growth and shrinkage of precipitates and voids. The curves labelled 1 to 5 show growth of the precipitates, followed by saturation and then shrinkage of the voids after the precipitate to void transformation. The linear regions of the growth and shrinkage are highlighted by rectangles for curve-1 as an example. Typical BF-TEM pictures of these dynamics are shown in Fig.2. Based on the data in this figure, the growth and shrinkage rates are $25 \pm 4$ and $38 \pm 6$ $n m^{2}$ per unit fluence, respectively.

\subsection{Effects of cooling and room-temperature Xe implantation}

After implantation at $873 \mathrm{~K}$ up to $1.24 \times 10^{16} \mathrm{Xe} . \mathrm{cm}^{-2}$, the specimen was cooled to $295 \mathrm{~K}$. This was done to decrease the internal pressure of the precipitates and form under-pressurized precipitates (due to thermal contraction of the Xe). BF-TEM micrographs at $873 \mathrm{~K}$, taken just before cooling of the specimen, are shown in column C1 in Fig. 4 in under and over-focussed imaging conditions. After waiting for about 12 minutes at $295 \mathrm{~K}$ to make sure that a stable temperature was attained, BF-TEM images were taken as shown in column C2 in Fig. 4. The specimen was then implanted with Xe ions and the dynamics of the behaviour of the precipitates and voids was captured using insitu videos as shown in the video clip SV02 in the SI. Unlike the behaviour at $873 \mathrm{~K}$, where precipitates grew until their transformation into voids, the precipitates and the voids at $295 \mathrm{~K}$ immediately started to shrink upon ion implantation. After a certain degree of shrinkage and stabilization, the precipitates transformed into voids which then continued to shrink further and eventually closed (a few video stills are shown in Fig. S2 in the SI). A BFTEM micrograph of the precipitates after implantation with $2.7 \times 10^{15} \mathrm{Xe}_{\mathrm{cm}} \mathrm{cm}^{-2}$ at $295 \mathrm{~K}$ shown in Fig. 4 (C3) clearly demonstrates that all the precipitates shrank in size. The two bright features indicated by the arrows in $\mathrm{C} 1$ disappeared after implantation whereas the features numbered 9 and 10 significantly reduced in size and are visible as very small precipitates in Fig. 4 (C3). This shows that the features indicated by the arrows were in fact voids and the features numbered 9 and 10 were very low-density precipitates - i.e. gaseous bubbles. TEM diffraction patterns at high temperature as well as at room temperature did not show any signs of crystalline Xe (note that at $300 \mathrm{~K}, \mathrm{Xe}$ precipitates of a diameter of about $2.2 \mathrm{~nm}$ or less are needed to have crystalline Xe; P > $440 \mathrm{MPa}$ ). We have however observed solid FCC nanocrystalline Xe precipitates at $-130{ }^{\circ} \mathrm{C}$ in other work (to be published). 

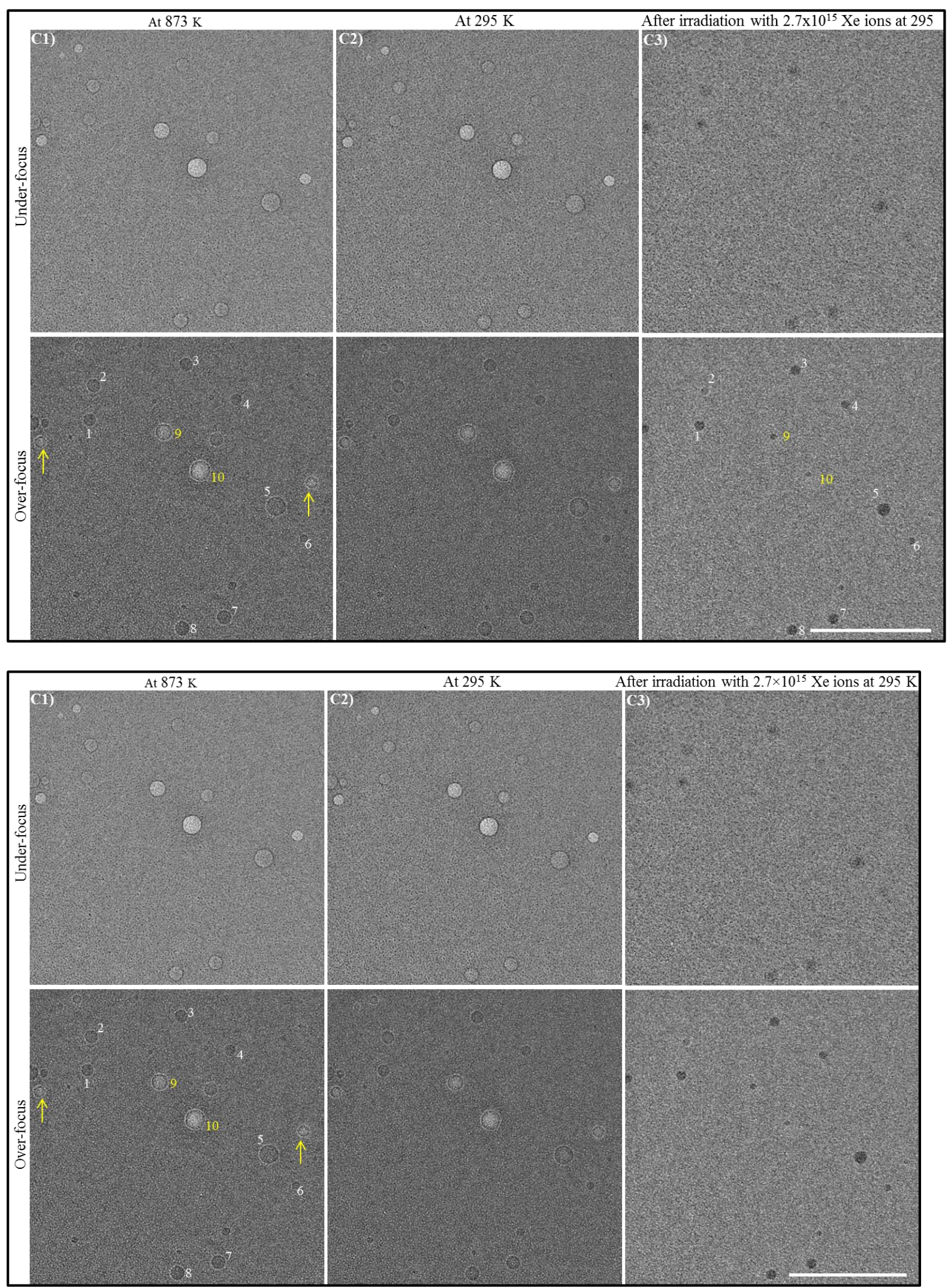

Figure-4: Under and over-focussed BF-TEM micrographs of Xe-irradiated a-SiO $\mathrm{O}_{2}$ in columns $\mathrm{Cl}$ to $\mathrm{C} 3$. (C1) a-SiO 2

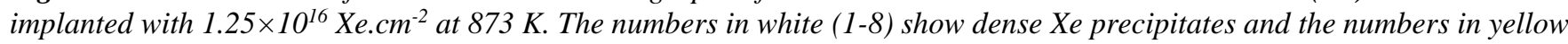
$(9,10)$ show low-density bubbles. The two features indicated by the arrows are voids. (C2) TEM micrograph taken on cooling the specimen to $295 \mathrm{~K}$. (C3) After implantation with $2.7 \times 10^{15} \mathrm{Xe}_{\mathrm{cm}} \mathrm{cm}^{-2}$ at $295 \mathrm{~K}$. (Defocus $=2 \mu \mathrm{m}$, scale bar= $\left.200 \mathrm{~nm}\right)$.

\section{Discussion}

4.1. The density of the precipitates 
The size, pressure, density and the number of Xe atoms present in the precipitates labelled 1-10 in Fig. 4 at $873 \mathrm{~K}$ are given in Table 1. The pressure is calculated based on the Young-Laplace equation $(\mathrm{P}=2 \gamma / \mathrm{r}$, where $\gamma$ is surface tension $\left(\sim 0.3 \mathrm{~N} . \mathrm{m}^{-1}\right.$ for $\left.\mathrm{a}-\mathrm{SiO}_{2}\right)$ and $\mathrm{r}$ is the precipitate radius). The density was calculated from Ronchi's data [28] shown in Fig. S3 in the SI (a detailed comparison of different equations of states and expected errors is given in our

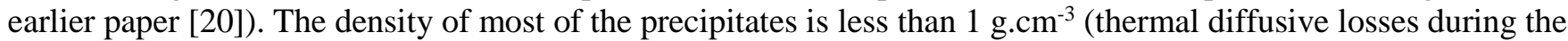
short time period of irradiation are ruled out due to very low Xe diffusion coefficient at this temperature $[23,29])$. This is in excellent agreement with our earlier experimental and simulation results [20] which showed that Xe precipitates in the density range of 0.5 to $1.5 \mathrm{~g} . \mathrm{cm}^{-3}$ are invisible in the at-focus images (like in Fig. 1(b)). A comparison of the diameters of the same precipitates before and after implantation with $2.7 \times 10^{15} \mathrm{Xe} . \mathrm{cm}^{-2}$ at $295 \mathrm{~K}$ is given in columns 2 and 3 in Table 2 . The data show that the bubbles/voids numbered 9 and 10 undergo a significant size reduction in comparison to others. The equilibrium pressure, density and the number of Xe atoms that should be present in the precipitates at $295 \mathrm{~K}$ after implantation with the Xe ions are given in columns 4 to 6 in Table 2 (the experimental pressure vs density data for Xe was taken from [30] and is shown in Fig. S3 in the SI). Although the precipitates are smaller at $295 \mathrm{~K}$ compared to their size at $873 \mathrm{~K}$, they contain a higher number of Xe atoms (compare column 5 of Table-1 with column 6 of Table 2) due to the additional ion implantation at $295 \mathrm{~K}$. This higher density also leads to their relatively darker contrast at $295 \mathrm{~K}$ as compared to their contrast at $873 \mathrm{~K}$.

Table-1: Diameter, pressure, density (Ronchi's data [28]) and the number of Xe atoms calculated to be present in the precipitates at $873 \mathrm{~K}$ numbered 1 to 10 in Fig.4.

\begin{tabular}{|l|l|l|l|l|}
\hline $\begin{array}{l}\text { Particle } \\
\text { number }\end{array}$ & $\begin{array}{l}\text { Diameter at } \\
\text { 873 K just } \\
\text { before cooling } \\
(\mathbf{n m})\end{array}$ & $\begin{array}{l}\text { Pressure } \\
(\mathbf{G P a})\end{array}$ & $\begin{array}{l}\text { Density at 900 K } \\
\left(\mathbf{g . c m}^{-3}\right)\end{array}$ & $\begin{array}{l}\text { Expected number of } \\
\text { Xe atoms in the } \\
\text { precipitates at 900 K }\end{array}$ \\
\hline 1 & 19 & 0.063 & 0.940 & 16664 \\
\hline 2 & 19 & 0.063 & 0.940 & 16281 \\
\hline 3 & 21 & 0.057 & 0.860 & 17900 \\
\hline 4 & 19 & 0.063 & 0.940 & 14599 \\
\hline 5 & 31 & 0.039 & 0.627 & 46091 \\
\hline 6 & 14 & 0.086 & 1.160 & 7322 \\
\hline 7 & 23 & 0.052 & 0.800 & 22004 \\
\hline 8 & 21 & 0.057 & 0.870 & 19463 \\
\hline 9 & 26 & 0.046 & 0.730 & 29073 \\
\hline 10 & 32 & 0.038 & 0.610 & 49418 \\
\hline
\end{tabular}

Table-2: Diameter, pressure, density (experimental data at $293 \mathrm{~K}$ [30]) and the number of Xe atoms present in the precipitates at 295 K numbered 1 to 10 in Fig.1.

\begin{tabular}{|l|l|l|l|l|l|}
\hline $\begin{array}{l}\text { Particle } \\
\text { number }\end{array}$ & $\begin{array}{l}\text { Diameter at } \\
\text { 295 K after } \\
\text { cooling (nm) }\end{array}$ & $\begin{array}{l}\text { Diameter after } \\
\text { irradiation at } \\
\text { 295 K (nm) }\end{array}$ & $\begin{array}{l}\text { Pressure } \\
(\mathbf{G P a})\end{array}$ & $\begin{array}{l}\text { Density } \\
\text { (experimental) }\end{array}$ & $\begin{array}{l}\text { Expected number } \\
\text { of Xe atoms in the } \\
\text { precipitates after } \\
\text { irradiation }\end{array}$ \\
\hline 1 & 21 & 16 & 0.075 & 2.500 & 23505 \\
\hline 2 & 21 & 12 & 0.100 & 2.730 & 10235 \\
\hline 3 & 20 & 16 & 0.075 & 2.500 & 23326 \\
\hline 4 & 17 & 13 & 0.092 & 2.680 & 15453 \\
\hline 5 & 30 & 19 & 0.063 & 2.530 & 41286 \\
\hline 6 & 12 & 10 & 0.120 & 2.800 & 7327 \\
\hline 7 & 21 & 16 & 0.075 & 2.500 & 23594 \\
\hline 8 & 23 & 16 & 0.075 & 2.500 & 24503 \\
\hline 9 & 25 & 8 & 0.150 & 2.820 & 3873 \\
\hline 10 & 32 & 7 & 0.171 & 2.840 & 1961 \\
\hline
\end{tabular}


By following the behaviour of Xe precipitates in-situ we showed that the precipitates grow in size and reach a steady state. The voids on the other hand only shrank under ion implantation. Furthermore, the voids shrank at a higher rate than the growth rate of the precipitates. Therefore, if one were to start with a specimen with an equal number of precipitates and voids with the same size distribution, the areal void density would decrease and result in a shift of the size distributions upon ion implantation. Slow growth and the tendency of the precipitates to saturate will lead to a higher areal density of precipitates than the voids. This was discussed previously [20] where it was shown that the areal void density is almost an order of magnitude less than the precipitate areal density (at room temperature, typical void and precipitate areal densities were about $2 \times 10^{9}$ and $2 \times 10^{10} \mathrm{~cm}^{-2}$, respectively; see Fig. S6 in the SI). Of a more fundamental nature is the question as to whether the precipitates grow under equilibrium conditions and the possibility of deviation from the equilibrium state. By evaluating the number of ion impacts received by the precipitates during their growth (by integrating the linear growth region in Fig. 3) and by calculating the resulting increase in the projected area of the precipitates due to these implanted ions, an area increase of $0.048 \pm 0.016 \mathrm{~nm}^{2}$ per Xe ion impact was obtained (the error is the standard deviation of the growth rates obtained from various curves shown in Fig 3). It simply means that each implanted ion increases the precipitate projected area by about $0.048 \mathrm{~nm}^{2}$. However, this does not necessarily imply that the implanted ion itself stopped within the precipitate and resulted in the growth. Figure 5 shows the increase in the precipitate area with the addition of Xe atoms at $873 \mathrm{~K}$ under equilibrium conditions based on Ronchi's density data (see Fig. S3, table ST1 and the associated description for the calculations in the SI). The slope of the line in Fig. 5 shows that under equilibrium conditions, the addition of each Xe atom increases the precipitate area by $0.0161 \pm 1.8 \times 10^{-4}$ $\mathrm{nm}^{2}$ only (the error is the error in the slope of the line). This is about three times smaller than the value obtained from the implantation data shown in Fig 3 - which indicated that each implanted Xe ion increases the precipitate area by $0.048 \pm 0.016 \mathrm{~nm}^{2}$. This is despite the fact that only a small fraction of the implanted ions will be stopped within the precipitates themselves. However, this does not take into account the fact that the Xe precipitates expand into a matrix already enriched in Xe atoms. The surrounding matrix may therefore be able to supply additional Xe atoms to the growing precipitates resulting in a higher growth rate than one might expect from the implanted atoms alone. By looking at the images in Fig. 2 and the curves in Fig 3, it is clear that the various precipitates emerge and start growing at different times or fluences. Therefore, the various precipitates expand into a matrix that is probably enriched with $\mathrm{Xe}$ atoms to varying extents. Considering the fluence corresponding to the midpoint of the linear region of the growth curves in Fig. 3 as the fluence for the estimation of Xe concentration in the matrix, we obtain Xe concentrations of $3.7 \times 10^{21}, 3.7 \times 10^{21}, 3.7 \times 10^{21}, 3.0 \times 10^{21}$ and $3.0 \times 10^{21} \mathrm{~cm}^{-3}$ for curves $1-5$, respectively. Next, we take the areas corresponding to the midpoint of the growth curve (column 2 in Table 3 ) and calculate the volume increase per implanted ion (column-4 in Table 3) based on the assumption that each Xe atom under equilibrium condition should increase the area by $0.0161 \mathrm{~nm}^{2}$ (from Fig. 5). Now the number of Xe atoms present in this additional volume ( $\mathrm{N}_{\text {matrix }}$ ) based on the Xe concentration in the matrix can be calculated (column 5 in Table 3 ). Thus, the precipitate at most receives a total of $\mathrm{N}_{\text {matrix }}+1 \mathrm{Xe}$ atoms. Finally, the increase in the precipitate area due to these $\mathrm{N}_{\text {matrix }}+1$ atoms at an expansion rate of $0.0161 \mathrm{~nm}^{2}$ per atom based on the equilibrium density data is calculated and shown in column- 6 of Table 3. The data shows that the area should increase at a rate of $0.04 \pm 0.002$ $\mathrm{nm}^{2}$ per ion. This is in excellent agreement with a value of $0.048 \pm 0.016 \mathrm{~nm}^{2}$ per ion impact obtained from the growth curve of the precipitates shown in Fig 3. This means that the global effect of each implanted ion is to bring some additional $\mathrm{Xe}$ atoms from the surrounding matrix into the precipitate which grows at a faster rate but under equilibrium conditions. On average, each implanted Xe atoms brings an additional $1.5 \mathrm{Xe}$ atoms from the matrix into the precipitate (column 5, Table 3). The precipitate thus grows at a rate commensurate with the addition of about 2.5 Xe atoms per implanted Xe ion under equilibrium conditions. These results show that no effective precipitate re-solution takes place when the matrix itself is saturated with gas atoms (the typical Xe density in the surrounding matrix is calculated to be about $3 \times 10^{21} \mathrm{~cm}^{-3}$. This is almost the Xe-precipitate number density which ranges from $2 \times 10^{21}$ to $4 \times 10^{21}$ at $900 \mathrm{~K}$ ). Furthermore, the results highlight that it is possible to ascertain with sufficient confidence that the precipitates grow purely under equilibrium conditions with surface tension balancing the pressure. 


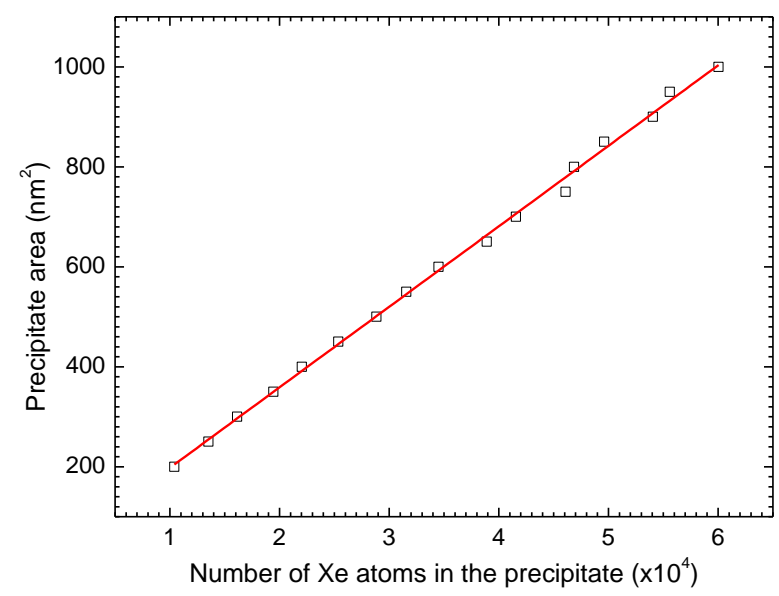

Figure-5: The number of Xe atoms expected to be present in the equilibrium precipitates of various sizes at $873 \mathrm{~K}_{\text {in }}$ a-SiO $\mathrm{O}_{2}$ The equilibrium growth rate (slope) is $0.0161 \pm 1.8 \times 10^{-4} \mathrm{~nm}^{2}$. atom ${ }^{-1}$.

Table-3: Effect of the implanted Xe atoms on the precipitate area and volume. $N_{\text {matrix }}$ is the number of Xe atoms present in the a-SiO $\mathrm{O}_{2}$ matrix into which the precipitates expand due to implantation. Volume of the precipitates was calculated by evaluating the radius from the area and assuming spherical precipitates.

\begin{tabular}{|c|c|c|c|c|c|}
\hline $\begin{array}{l}\text { Number of the } \\
\text { implanted ions }\end{array}$ & $\begin{array}{l}\text { Area of the } \\
\text { precipitate } \\
\quad\left(\mathbf{n m}^{2}\right)\end{array}$ & $\begin{array}{c}\text { Volume of the } \\
\text { precipitate } \\
\left(\mathrm{cm}^{3}\right)\end{array}$ & $\begin{array}{l}\text { Volume increase } \\
\text { by the implanted } \\
\text { ion }\end{array}$ & $\begin{array}{l}\text { Number of Xe atoms in } \\
\text { this volume based on } \\
\text { the concentration of } \\
\text { pre-existing } X e \text { in the } \\
\text { matrix ( } N_{\text {matrix})}\end{array}$ & $\begin{array}{c}\text { Total Area } \\
\text { increase due to } \\
\mathbf{N}_{\text {matrix }}+1 \text { Xe atoms } \\
\left(\mathbf{n m}^{2}\right)\end{array}$ \\
\hline 0 & 950 & $2.2032 \mathrm{E}-17$ & & & \\
\hline 1 & 950.0161 & $2.2033 \mathrm{E}-17$ & $5.601 \mathrm{E}-22$ & 1.7 & 0.043 \\
\hline 0 & 750 & $1.5455 \mathrm{E}-17$ & & & \\
\hline 1 & 750.0161 & $1.5455 \mathrm{E}-17$ & $4.977 \mathrm{E}-22$ & 1.5 & 0.040 \\
\hline 0 & 430 & $6.7093 \mathrm{E}-18$ & & & \\
\hline 1 & 430.0161 & $6.7097 \mathrm{E}-18$ & $3.768 \mathrm{E}-22$ & 1.4 & 0.038 \\
\hline 0 & 450 & $7.1828 \mathrm{E}-18$ & & & \\
\hline 1 & 450.0161 & 7.1832E-18 & $3.855 \mathrm{E}-22$ & 1.4 & 0.039 \\
\hline 0 & 580 & $1.0510 \mathrm{E}-17$ & & & \\
\hline 1 & 580.0161 & $1.0511 \mathrm{E}-17$ & $4.376 \mathrm{E}-22$ & 1.6 & 0.042 \\
\hline
\end{tabular}

Once the maximum precipitate growth is achieved, saturation or at least a significant drop from the linear growth as evident from the curves in Fig. 3 is observed. During this brief stage of the saturation, it is possible that precipitate over-pressurization may take place (other scenarios are discussed later on). If so, the degree of over-pressurization can be estimated from the curves in Fig. 3. Once the saturation of a precipitate is reached, any additional ion implantation into the precipitate will lead to over-pressurization. The details of this calculation are given in Fig. S4 and the associated description in the SI and indicate that under these conditions ( $873 \mathrm{~K}$ ) over-pressurization can range from about $10 \%$ (3 MPa) to about $30 \%(10 \mathrm{MPa})$ at most.

An alternative hypothesis would be to assume that there is no over-pressurization at all. The departure from linear growth and saturation of the precipitate sizes could also be explained by the implantation profile. Since the implanted Xe concentration drops away from the centre of the implantation profile (see Fig-S1 in the SI), as the precipitates grow in size, the top and bottom regions of the precipitates progressively expand into a matrix that is deficient in Xe content. Thus, the matrix cannot supply enough Xe atoms to the precipitate to keep it growing at the initial rate. This would be observed in the in-situ experiments reported here as a drop from the linear growth trend and eventually saturation. One way to test this hypothesis would be to implant the specimens with multienergy Xe ions to maintain a uniform Xe concentration. In such a scenario, there should only be linear growth without any tendency to saturate (although coalescence may eventually play a role in controlling the growth behaviour in this case). 


\subsection{Ballistic thermal spikes and Xe diffusion}

The growth rate of the precipitates indicates that each implanted ion incorporates additional Xe atoms from the matrix into the precipitate. But the question remains as to how this may actually take place. A plausible hypothesis is that the Xe ion impact causes an intense local melting referred to as ballistic melting near the precipitate-matrix interface. Under the influence of this temperature spike, Xe atoms present in the immediate vicinity may diffuse into the precipitate. On cooling, the precipitate will contain additional Xe atoms from the matrix and a new equilibrium precipitate size is established. The new size of the precipitate is effectively dictated by $\mathrm{N}_{\text {matrix }}+1 \mathrm{Xe}$ atoms ( 2.5 atoms) that manage to diffuse into the precipitate during the ballistic thermal spike phase. The typical $\mathrm{Xe}$ density in the surrounding matrix is about $3 \times 10^{21} \mathrm{~cm}^{-3}$. Therefore, it would require a volume of about $10^{-21} \mathrm{~cm}^{3}$ to supply the required $2.5 \mathrm{Xe}$ atoms for the precipitate growth. If we assume that as the ion transverses the matrixprecipitate interface (or precipitate-matrix interface on the exit side) a molten volume of this size surrounding the precipitate is created, it would require a hemisphere of about $0.6 \mathrm{~nm}$ radius surrounding the precipitate (hemisphere because the other side is bound by the precipitate itself). If the same melting events take place on the entry and exit locations of the matrix-precipitate-matrix interface, then a hemisphere of $0.3 \mathrm{~nm}$ only on either side of the precipitate is needed (note that if one assumes that only half of the Xe atoms in the molten volume diffuse towards one side of the hemisphere and the other half diffuse towards the opposite side, then these limits are 1.2 to $0.6 \mathrm{~nm}$, respectively). If the typical time period of the thermal spike is taken to be about $10^{-11} \mathrm{~s}$, then it would require a Xe diffusion coefficient of about $10^{-5}$ to $10^{-6} \mathrm{~cm}^{2} . \mathrm{s}^{-1}$ for the Xe atoms from the farthest end of the molten volume of the hemisphere to cross the matrix-precipitate interface. Based on published experimental values for the Xe diffusion coefficient [29], a matrix temperature of about $3500 \mathrm{~K}$ would be required. In order to see whether such temperatures can be reached during $45 \mathrm{keV} \mathrm{Xe}$ ion implantation, thermal spike simulations for a-SiO $\mathrm{S}_{2}$ using the unified-thermal spike model [31] were performed for the specimen at $295 \mathrm{~K}$ and $873 \mathrm{~K}$. The temperature profiles as a function of time for various radial distances from the location of ion impact are shown in Fig.6. It shows that the regions within a radial distance of about $0.6 \mathrm{~nm}$ are heated to more than $3500 \mathrm{~K}$ for about $5 \mathrm{ps}$ for implantation at $873 \mathrm{~K}$. The temperature at a radial distance of about $0.2 \mathrm{~nm}$ remains close to $3000 \mathrm{~K}$ for up to $10 \mathrm{ps}$. At $295 \mathrm{~K}$, the temperature at a radial distance of about $0.2 \mathrm{~nm}$ remains higher than $2300 \mathrm{~K}$ and up to about $3500 \mathrm{~K}$ for about 3 ps. Thus, ballistic spikes should be capable of mobilizing the Xe atoms from the matrix into the precipitate. This, in essence, is the same as the phenomenon of ion-beam mixing invoked in cryogenic temperature irradiations of metal matrices with trace metal impurities where ballistic collisions have been observed to trigger the diffusion of the trace elements during the ballistic phase [32]. It is important to bear in mind that ballistic spikes occurring inside the Xe precipitate and near the interface may have a similar effect on the surrounding matrix as the precipitate-glass interface will be subjected to a temperature increase due to the heat transfer from the Xe precipitate. Thus ballistic spikes near the matrix-precipitate interface or inside the precipitate both have the potential of bringing in extra Xe from the matrix into the precipitates. Therefore, as the ion implantation continues, the matrix-precipitate is continuously subjected to these thermal spike events which aid Xe diffusion and precipitate growth. From this perspective, it would be interesting in future to study in detail the effect of ion energy on the growth rate of the precipitates as this would allow to tailor the temperature during the ballistic spikes.

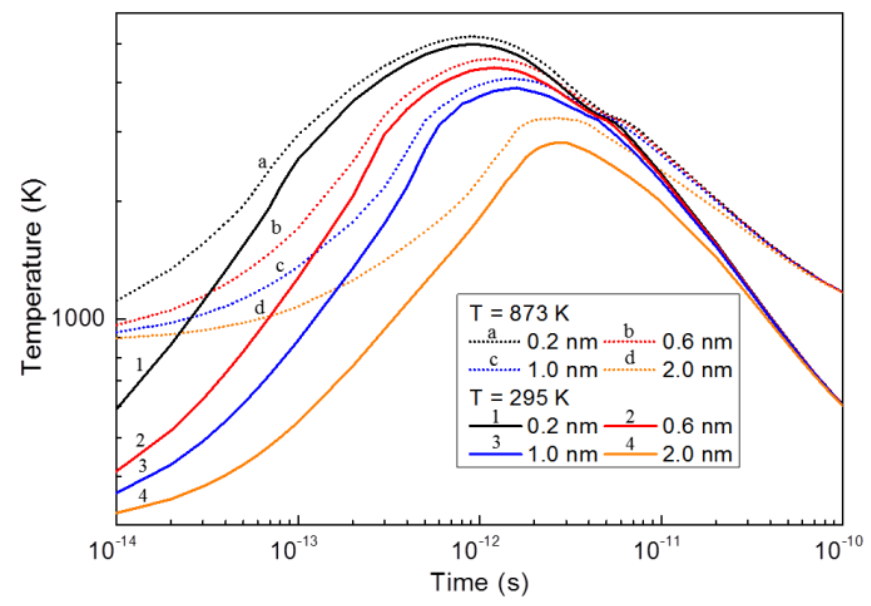

Figure-6: Thermal spike simulation of $45 \mathrm{keV} \mathrm{Xe} \mathrm{implantation} \mathrm{of} \mathrm{a-SiO}{ }_{2}$. The temperatures are shown as a function of radial distance ( $\mathrm{nm}$ ) from the ion impact. The calculations were carried out for matrix temperatures of $295 \mathrm{~K}$ (solid lines) and $873 \mathrm{~K}$ (dotted lines). 
A comparison of the Xe density at $295 \mathrm{~K}$ and $873 \mathrm{~K}$ is given in Fig. S3 in the SI. It shows that the Xe density at $295 \mathrm{~K}$ is about three times higher than the Xe density at $873 \mathrm{~K}$ for a given pressure. Since the glass boundary surrounding the precipitate does not move inwards on cooling the specimen (the linear thermal coefficient of a$\mathrm{SiO}_{2}$ is very small and close to about $6 \times 10^{-7} \mathrm{~K}^{-1}$ in the temperature range of interest [33]) and Xe still exists as a supercritical fluid (critical $\mathrm{T}$ and $\mathrm{P}$ of $\mathrm{Xe}=289 \mathrm{~K}$ and $5.8 \mathrm{MPa}$, respectively), cooling the specimen to $295 \mathrm{~K}$ results in a decrease of the precipitate pressure. From Fig. S3 in the SI, one can estimate that most of the precipitates experience a depressurization of about $50 \mathrm{MPa}$ and precipitate pressure is now only 6 to $8 \mathrm{MPa}$; this is just higher than the critical pressure (or $10-18 \mathrm{MPa}$ if the over-pressurization at $873 \mathrm{~K}$ is also considered). As even the most over-pressurized precipitates at $873 \mathrm{~K}$ are densified by a factor of only 1.2 above the equilibrium value, both the equilibrium precipitates and any over-pressurized precipitates at $873 \mathrm{~K}$ will become highly underpressurized on cooling to room temperature. Therefore, one would expect these under-pressurized precipitates to behave somewhat like voids to further ion implantation due to a lack of sufficient internal pressure. This is exactly, what was observed during implantation at $295 \mathrm{~K}$, where precipitates shrank before reaching a steady state and subsequently transformed into voids. It is therefore plausible to assume that after shrinking and stabilization, the precipitates are again in equilibrium with the surrounding matrix (indeed, this may be the best way of making equilibrium precipitates). The equilibrium pressure, density and the number of Xe atoms in the precipitates shown in Fig. 4 (C3) are given in columns 4 to 6 in Table-2. A comparison of the number of Xe atoms that should be present in the precipitates under the equilibrium conditions (column 6 in Table-2) with the number of atoms present in these precipitates before the implantation (i.e. at $873 \mathrm{~K}$ ) plus the newly implanted Xe ions at $295 \mathrm{~K}$ is given in Fig. 7 (see Fig. S5 and the associated description in the SI). A close agreement between these two shows that the new state is indeed an equilibrium state and that the new precipitate size is dictated by the implanted Xe ions and the Xe atoms that were already present in the precipitates at $873 \mathrm{~K}$. Furthermore, it shows that the implanted Xe ions do not move a significant number of Xe atoms from the matrix into the precipitates. One possible explanation for this is that cooling increases the number density of the Xe precipitates by a factor of three effectively decreasing the Xe concentration gradient between the matrix and the precipitates. Consequently, the diffusion from the matrix into the precipitates is reduced. In addition, a lower matrix temperature ( $295 \mathrm{~K}$ vs. $873 \mathrm{~K})$ also aids in reducing the Xe diffusion during the ballistic thermal spike as somewhat lower temperatures are reached during the thermal spike (Fig. 6). An additional possibility would be a more dominant precipitate re-solution at $295 \mathrm{~K}$ due to the ballistic collisions now taking place inside much denser Xe precipitates such that the net Xe flux coming into the precipitates is reduced in comparison to the net incoming Xe flux at $873 \mathrm{~K}$.

It is reasonable to propose that the degree of precipitate shrinkage at $295 \mathrm{~K}$ depends on the degree of deviation from the equilibrium state at $873 \mathrm{~K}$. The larger the deviation, the higher the degree of shrinkage (for the case of under-pressurization). This is supported by precipitates numbered 9 and 10, which showed significant shrinking as compared to others, primarily because they are under-pressurized/low-density bubbles as indicated by their light contrast more closely resembling the voids. In addition, one would expect a relatively smaller degree of shrinkage in the over-pressurized precipitates as compared to the equilibrium precipitates. Fundamentally, the shrinkage of the under-pressurized precipitates is no different from the behaviour of the voids which show complete closure due to ion implantation. It is simply due to a lack of internal pressure in the case of voids that a complete closure is seen whereas the precipitates, due to the presence of Xe atoms, resist this closure and attain an equilibrium state. Molecular dynamics simulations on the behaviour of noble gas precipitates and voids in Si have been performed previously [26]. These studies have shown that viscous flow and momentum transfer during the ballistic collisions directs the matrix material towards the precipitates/cavities. From these studies, it is understood that the lack of any internal pressure in the case of a cavity means there is no resistance to prevent the inward mass flow whereas precipitates offer a barrier to the inward mass flow thus preventing closure. In the current work, when underpressurized precipitates are subjected to ballistic collisions, the internal pressure is positive but still not enough to completely counter the inward mass flow. Therefore, the outer boundary of the precipitates continues to shrink until an equilibrium pressure is reached which then prevents any further inward flow. 


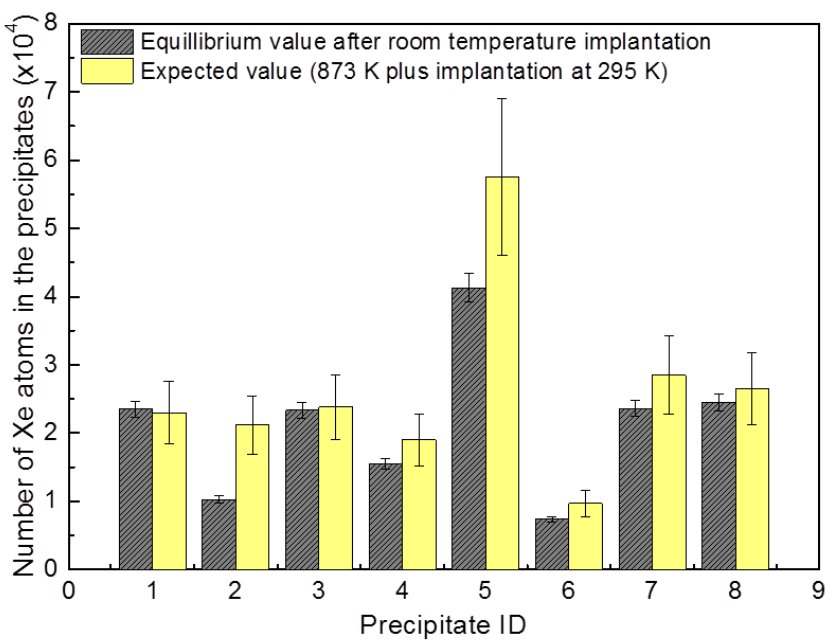

Figure-7: Number of Xe atoms in the equilibrium Xe precipitates at $295 \mathrm{~K}$ (black with mesh) and the number of Xe atoms expected to be present based on the equilibrium at $873 \mathrm{~K}$ plus the addition of more Xe atoms after implantation at $295 \mathrm{~K}$ (red).

Based on the results and the discussion above, a simplified picture of the precipitate growth at $873 \mathrm{~K}$ and shrinkage at $295 \mathrm{~K}$ is presented in Fig. 8. Panel-A shows an equilibrium precipitate at $873 \mathrm{~K}$ surrounded by the Xe containing glass matrix. After an ion impact, a transient state at high-temperature due to ballistic melting (as shown in panel$\mathrm{B}$ ) is created. Apart from some Xe ions stopping in the precipitate itself, additional Xe atoms from the matrix are thermally driven from the matrix into the precipitate during the ballistic phase. On cooling, the precipitate attains a new equilibrium state at larger size (panel-C) containing on average 2.5 additional Xe atoms per implanted Xe. The new equilibrium precipitate at $873 \mathrm{~K}$ is shown in panel-D which is shown after cooling to $295 \mathrm{~K}$ in panel-E. Panel E shows an under-pressurized precipitate because a temperature decrease from 873 to $295 \mathrm{~K}$ leads to

depressurization by about $50 \mathrm{MPa}$ (placing the Xe atoms close together in the figure implies only that the pressure on the precipitate boundary is less). However, the precipitate size does not change as the glass interface defining the boundary of the precipitate is rigid and not prone to thermal compression. Ion implantation causes an inward motion of the matrix boundary and leads to a collapse of the under-pressurized precipitate. A new equilibrium state defined by the already present Xe atoms and about $45 \%$ of the newly implanted Xe atoms as shown in panel-F is then established. 


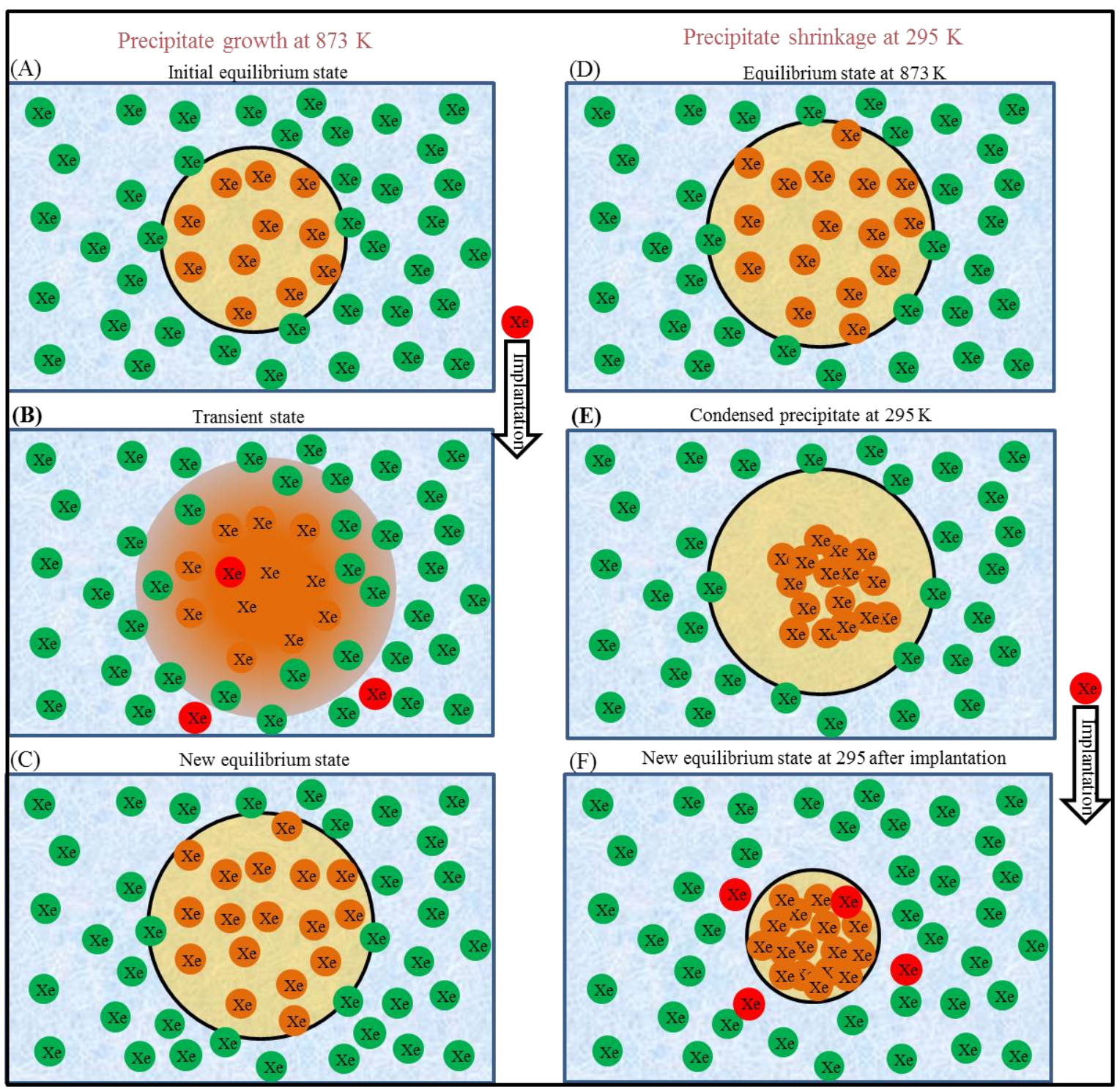

Figure-8: A schematic of precipitate growth at $873 \mathrm{~K}$ (panels $A-C$ ) and precipitate shrinkage at $295 \mathrm{~K}$ (panels D-F). The numbers of Xe spheres are indicative only and do not reflect the real densities (see text for details).

\section{Conclusion}

This study focused on the behaviour of Xe precipitates in a- $\mathrm{SiO}_{2}$ under $45 \mathrm{keV} \mathrm{Xe}$ ion implantation at 873 and continued then at $295 \mathrm{~K}$. At $873 \mathrm{~K}$, the precipitates were shown to grow under equilibrium conditions before reaching a steady state. The projected precipitate area (as seen in TEM) grew at a rate of $0.048 \pm 0.016 \mathrm{~nm}^{2}$ per implanted ion equivalent with the addition of $2.5 \mathrm{Xe}$ atoms per implanted Xe under equilibrium conditions. The additional Xe atoms are driven from the Xe saturated matrix into the precipitate under the influence of ballistic thermal spike which enables Xe diffusion. The results demonstrate that no effective re-solution takes place when the matrix itself is saturated with the gas atoms. After the saturation size is attained, the precipitates could be overpressurized by about 3 to $10 \mathrm{MPa}$ (10 to $30 \%$ of over-pressurization) due to further implantation until they transform into voids. The voids, once formed, shrink in size, and eventually close under further ion implantation. After the initial precipitate formation at equilibrium conditions, the specimen contains a mixture of equilibrium precipitates, under-pressurized precipitates, voids and possibly some over-pressurized precipitates at higher fluences. The under-pressurized precipitates are mainly a result of the partial release of Xe atoms from the precipitates during precipitate to void transformation. The only time during which all the precipitates are in equilibrium with the matrix is before the saturation of the precipitate sizes and the formation of voids.

On cooling of the specimen to $295 \mathrm{~K}$, the equilibrium (as well as any over-pressurized precipitates) are left underpressurized due to thermal contraction of the $\mathrm{Xe}$ and insignificant relaxation of the surrounding a-SiO $\mathrm{O}_{2} \mathrm{matrix}$. When these under-pressurized precipitates are subjected to further implantation at room temperature, they readily contract and continue to do so until a new equilibrium state is achieved. The new equilibrium state is determined by 
the number of Xe atoms already present in the precipitates when cooling from $873 \mathrm{~K}$ and the newly added Xe atoms during room temperature implantation. The precipitates eventually transform into voids which are unstable during continued Xe implantation and close as observed at high-temperature. Comparing the behaviour of the voids and under-pressurized precipitates, it is clear that a sufficient internal pressure is necessary for radiation stability of the inclusions (precipitates and voids). Lack of significant internal pressure allows the viscous and convective flow of the surrounding matrix towards the inclusions under the influence of ballistic collisions and resultant thermal spike. The internal pressure provides the resistance to inward mass flow and prevents the collapse of the inclusions. These results highlight that atomistic simulations looking into the physical aspects of precipitate growth and homogeneous resolution should take into account the saturation state of the matrix to correctly understand the degree of precipitate re-solution. They further show that the degree of over-pressurization, if any at all, is not very significant and precipitates grow mostly under equilibrium conditions.

\section{Acknowledgements}

The authors are thankful to the Engineering and Physical Sciences Research Council for funding under grants EP/E017266/1, EP/M011135/1 and EP/M028283/1.

\section{Data Availability}

The raw/processed data required to reproduce these findings cannot be shared at this time due to technical limitations (each image/video file size ranging from a minimum of $64 \mathrm{MB}$ to hundreds of MB), but, can be made available on request as individual files. 


\section{References}

[1] S.E. Donnelly, The Density and Pressure of Helium in Bubbles in Implanted Metals: A Critical Review, Radiat. Eff. 90 (1985) 1-47. doi:10.1080/00337578508222514.

[2] M. Song, K. Mitsuishi, K. Furuya, C.W. Allen, R.C. Birtcher, S.E. Donnelly, Structure of nanometre-sized Xe particles embedded in Al crystals, J. Microsc. 215 (2004) 224-229. doi:10.1111/j.0022-2720.2004.01369.x.

[3] H. Van Swijgenhoven, G. Knuyt, J. Vanoppen, L.M. Stals, Helium bubble growth in nickel at temperatures below vacancy migration, J. Nucl. Mater. 114 (1983) 157-167. doi:10.1016/0022-3115(83)90253-2.

[4] S.E. Donnelly, R. Birtcher, C. Templier, V.Vishnyakov, Response of helium bubbles in gold to displacement-cascade damage, Phys. Rev. B. 52 (1995) 3970.

[5] R.C.Birtcher, S.E.Donnelly, T. Templier, Evolution of helium bubbles in aluminium during heavy-ion irradiation, Phys. Rev. B. 50 (1994) 764.

[6] J. Rest, R.C. Birtcher, Precipitation kinetics of rare gases implanted into metals, J. Nucl. Mater. (1989) $312-325$.

[7] N. Marochov, P.J. Goodhew, A comparison of the growth of helium and neon bubbles in nickel, J. Nucl. Mater. 158 (1988) 81-86. doi:10.1016/0022-3115(88)90157-2.

[8] J.H. Evans, D.J. Mazey, Evidence for solid krypton bubbles in copper, nickel and gold at 293K, J. Phys. F Met. Phys. 15 (1985). doi:10.1088/0305-4608/15/1/001.

[9] C.J. Rossouw, S.E. Donnelly, Superheating of small solid-argon bubbles in aluminum, Phys. Rev. Lett. 55 (1985) 2960-2963. doi:10.1103/PhysRevLett.55.2960.

[10] A. Vom Felde, J. Fink, T. M̈ller-Heinzerling, J. Pfïger, B. Scheerer, G. Linker, D. Kaletta, Pressure of neon, argon, and xenon bubbles in aluminum, Phys. Rev. Lett. 53 (1984) 922-925. doi:10.1103/PhysRevLett.53.922.

[11] A. Caro, D. Schwen, E. Martinez, Structure of nanoscale gas bubbles in metals, Appl. Phys. Lett. 103 (2013). doi:10.1063/1.4833775.

[12] V. Vishnyakov, S.E. Donnelly, G. Carter, R. Birtcher, L. Haworth, Helium Bubble Growth in Silicon: Ripening or Bubble Motion and Coalescence?, Solid State Phenom. 82-84 (2002) 267-272. doi:10.4028/www.scientific.net/SSP.82-84.267.

[13] M.O. Ruault, F. Fortuna, H. Bernas, M.C. Ridgway, J.S. Williams, How nanocavities in amorphous Si shrink under ion beam irradiation: An in situ study, Appl. Phys. Lett. 81 (2002) 2617-2619. doi:10.1063/1.1509854.

[14] X.F. Zhu, J.S. Williams, M.J. Conway, M.C. Ridgway, F. Fortuna, M.O. Ruault, H. Bernas, Direct observation of irradiation-induced nanocavity shrinkage in Si, Appl. Phys. Lett. 79 (2001) 3416-3418. doi:10.1063/1.1413497.

[15] L. Pagano, A.T. Motta, R.C. Birtcher, The formation of bubbles in $\mathrm{Zr}$ alloys under Kr ion irradiation, J. Nucl. Mater. 244 (1997) 295-304. doi:10.1016/S0022-3115(96)00757-X.

[16] G. Knuyt, M. D’Olieslaeger, L. De Schepper, L.M. Stals, Theoretical description of helium and argon bubble growth in an amorphous alloy, Philos. Mag. A Phys. Condens. Matter, Struct. Defects Mech. Prop. 57 (1988) 277-300. doi:10.1080/01418618808204516.

[17] H.V.A.N. Swygenhoven, Helium implantation of an Fe-Ni-Mo-B amorphous alloy II. A Free-volume relaxation model for bubble growth in amorphous alloys, J. Nucl. Mater. 18 (1983) 134-142.

[18] R. Evron, Y. Cohen, O. Regev, Y. Eyal, H. Matzke, K. Tinschert, Ion implantation induced microstructural damage in a nuclear waste glass, Nucl. Soc. Isr. 18 (1994) VIII-2-VIII-7.

[19] G. Gutierrez, S. Peuget, J.A. Hinks, G. Greaves, S.E. Donnelly, E. Oliviero, C. Jégou, Helium bubble formation in nuclear glass by in-situ TEM ion implantation, J. Nucl. Mater. 452 (2014) 565-568. doi:10.1016/j.jnucmat.2014.06.010.

[20] A.H. Mir, J.A. Hinks, J.-M. Delaye, S. Peuget, S.E. Donnelly, Xenon solubility and formation of supercritical xenon precipitates in glasses under non-equilibrium conditions, Sci. Rep. 8 (2018) 15320. doi:10.1038/s41598-018-33556-y.

[21] C.A. Taylor, M.K. Patel, J.A. Aguiar, Y. Zhang, M.L. Crespillo, J. Wen, H. Xue, Y. Wang, W.J. Weber, Bubble formation and lattice parameter changes resulting from He irradiation of defect-fluorite $\mathrm{Gd} 2 \mathrm{Zr} 2 \mathrm{O} 7$, Acta Mater. 115 (2016) 115-122. doi:10.1016/j.actamat.2016.05.045.

[22] M.F. Beaufort, M. Vallet, J. Nicolaï, E. Oliviero, J.F. Barbot, In-situ evolution of helium bubbles in SiC under irradiation, J. Appl. Phys. 118 (2015). doi:10.1063/1.4936562.

[23] E. Ntsoenzok, H. Assaf, M.O. Ruault, S. Ashok, Xe implantation in SiO2: Low-k applications, ICSICT-2006 2006 8th Int. Conf. Solid-State Integr. Circuit Technol. Proc. (2007) 295-297. doi:10.1109/ICSICT.2006.306211.

[24] H. Assaf, E. Ntsoenzok, M.F. Barthe, M.O. Ruault, T. Sauvage, S. Ashok, Structural and nuclear characterizations of defects created by noble gas implantation in silicon oxide, Nucl. Instruments Methods Phys. Res. Sect. B Beam Interact. with Mater. Atoms. 253 (2006) 222-226. doi:10.1016/j.nimb.2006.10.042.

[25] J.H. Evans, An interbubble fracture mechanism of blister formation on helium-irradiated metals, J. Nucl. Mater. 68 (1977) 129-140. doi:10.1016/0022-3115(77)90232-X.

[26] M.A. Okunlewski, Y. Ashkenazy, B.J. Heuser, R.S. Averback, Molecular dynamics simulations of void and helium bubble stability in amorphous silicon during heavy-ion bombardment, J. Appl. Phys. 96 (2004) 4181-4188. doi:10.1063/1.1791759.

[27] J. Schindelin, I. Arganda-Carreras, E. Frise, V. Kaynig, M. Longair, T. Pietzsch, S. Preibisch, C. Rueden, S. Saalfeld, B. Schmid, J.Y. Tinevez, D.J. White, V. Hartenstein, K. Eliceiri, P. Tomancak, A. Cardona, Fiji: An open-source platform for biological-image analysis, Nat. Methods. 9 (2012) 676-682. doi:10.1038/nmeth.2019.

[28] C. Ronchi, Extrapolated equation of state for rare gases at high temperatures and densities, J. Nucl. Mater. 96 (1981) 
314-328. doi:10.1016/0022-3115(81)90575-4.

[29] K. Roselieb, W. Rammensee, H. Büttner, M. Rosenhauer, Diffusion of noble gases in melts of the system SiO2NaAlSi2O6, Chem. Geol. 120 (1995) 1-13. doi:10.1016/0009-2541(94)00117-Q.

[30] J.M.H. Levelt, The reduced equation of state, internal energy and entropy of argon and xenon, Physica. 26 (1960) 361377.

[31] M. Toulemonde, W.J. Weber, G. Li, V. Shutthanandan, P. Kluth, T. Yang, Y. Wang, Y. Zhang, Synergy of nuclear and electronic energy losses in ion-irradiation processes: The case of vitreous silicon dioxide, Phys. Rev. B. 83 (2011) 054106. doi:10.1103/PhysRevB.83.054106.

[32] S.J. Kim, M.A. Nicolet, R.S. Averback, D. Peak, Low-temperature ion-beam mixing in metals, Phys. Rev. B. 37 (1988) 38-49. doi:10.1103/PhysRevB.37.38.

[33] Y. Kikuchi, H. Sudo, N. Kuzuu, Thermal expansion of vitreous silica: Correspondence between dilatation curve and phase transitions in crystalline silica, J. Appl. Phys. 82 (1997) 4121-4123. doi:10.1063/1.366279. 